\title{
Comparison Objective Structured Assessment of Camera Navigation Skills Score-Pre- and Post-training Intervention
}

\author{
Hariyono Winarto ${ }^{1}$, Kade Yudi Saspriyana ${ }^{2}$, Aria Kekalih ${ }^{3}$
}

\begin{abstract}
Aim: Inexperienced operating assistants are often tasked with the important role of handling camera navigation during laparoscopic surgery. Incorrect handling can lead to poor visualization and increased operating time. The objective of this research was to examine benefit of camera navigation training in laparoscopic used pelvic box based on Objective Structured Assessment of Camera Navigation Skills (OSA CNS) assessment and explore factors correlated to difference skill after training.

Materials and methods: An experimental study (pre-post interventional study) was conducted at the training room of Indonesia Clinical Training and Education Centre (ICTEC) Faculty of Medicine Universitas Indonesia-Dr. Cipto Mangunkusumo Hospital (CMH), on December 2018 to January 2019. Participants were Obstetrics and Gynecology resident Medical Faculty of Universitas Indonesia. We did evaluation before training and 1, 2, 3 weeks after training used OSA CNS. Data analysis used paired- $t$ test.

Results: There were significant increasing OSA CNS score after camera navigation training used pelvic box. Average OSA CNS score before training and 1, 2, 3 weeks after training were $15.00 \pm 2.03,17.60 \pm 2.69,16.36 \pm 1.84,17.80 \pm 2.26$, respectively. Optimum duration of OSA CNS evaluation was 3 weeks after the training. Female gender and low experience were two factors influence camera navigation skill after the training. Conclusion: Laparoscopy camera navigation training used pelvic box could be applied to support residency program curriculum and there were increasing camera navigation skills after training used pelvic box. Female gender and low experience were factors significant correlate to training outcome of camera navigation skill used pelvic box.

Clinical significance: Camera navigation training used pelvic box is a critical component for teaching safe endoscopic practices in our Ob/Gyn residency training program.

Keywords: Camera navigation in laparoscopy, Objective structured assessment of camera navigation skills, Training.

World Journal of Laparoscopic Surgery (2020): 10.5005/jp-journals-10033-1405
\end{abstract}

\section{INTRODUCTION}

Laparoscopy surgery was becoming as one of the alternatives in gynecology surgery and have more benefits compared to open laparotomy. Laparoscopy technique needs specific skills rather than open laparotomy: camera navigation, orientation and depth of object in two dimension, hand-eye coordination, and good tissue handling. ${ }^{1,2}$

Curriculum guidance for Obstetrics and Gynecology residents emphasize that all off the members must be proficient to a number of laparoscopic procedures. But in other situation, they faced problems of teaching hospital condition related to restrict of services in the operating theater due to efficiency of hospital budget, decrease medical error based on hospital accreditation programs, and also related to ethical issue due to direct training to the patient. ${ }^{3-5}$

Laparoscopic surgery demands very specific skills and capabilities that require initial learning of cognitive and motor skills followed by refinement of those skills. The prerequisite for skilled laparoscopic work includes: (1) Depth perception. The surgeon is required to maneuver, tissues and instruments in a three-dimensional environment with two-dimensional view. (2) Adjustment to fulcrum effect. This creates conflict between visual and proprioceptive feedback. (3) Hand-eye coordination; (4) Bimanual manipulation; (5) Handling of laparoscopic instruments; and (6) Ambidexterity. Training in pelvic box can be used to fulfill all of those prerequisites' laparoscopic skills. ${ }^{6-8}$

Camera navigation in laparoscopy is often considered as a simple task and is handled by the less experienced, such as medical students or junior residents. It is, however, a complicated task, requiring specific psychomotor and visuospatial skills. Inappropriate handling of the camera results in poor visualization, which can

\begin{abstract}
1,2Department of Obstetrics and Gynecology, Oncogynecology Division, Dr. Cipto Mangunkusumo Hospital, Faculty of Medicine Universitas Indonesia, Jakarta, Indonesia

${ }^{3}$ Department of Community Health Program, Faculty of Medicine Universitas Indonesia, Jakarta, Indonesia

Corresponding Author: Hariyono Winarto, Department of Obstetrics and Gynecology, Oncogynecology Division, Dr. Cipto Mangunkusumo Hospital, Faculty of Medicine Universitas Indonesia, Jakarta, Indonesia, Phone: +62 81319399189, e-mail: hariyono.winarto@ui.ac.id
\end{abstract}

How to cite this article: Winarto $H$, Saspriyana KY, Kekalih A. Comparison Objective Structured Assessment of Camera Navigation Skills Score-Pre- and Post-training Intervention. World J Lap Surg 2020;13(2):69-73.

Source of support: Medical Faculty Universitas Indonesia

Conflict of interest: None

lead to longer operating time; surgeon frustration; and can, most importantly, compromise patient safety. An assessment tool was created, inspired by the Objective Structured Assessment of Surgical Skills (OSATS) assessment tool, with five items scored on 5 -point scales with anchors in the middle and at the ends. The tool named as Objective Structured Assessment of Camera Navigation Skills (OSA CNS). The evaluation cover view completion, horizontal alignment, scope orientation, instrument collision, and autonomy. Nilsson stated that minimally score of OSA CNS was 14 to achieve good result in camera navigation. ${ }^{4,6}$

Several factors could influence laparoscopic training outcome, such as age, gender, and interest to laparoscopy itself. Level of 
laparoscopic education, level of laparoscopic experience, and level of laparoscopic knowledge were factors related to training outcome based on fundamental laparoscopic surgery curriculum. ${ }^{5}$

The aim of this study is to investigate the comparison of camera laparoscopy navigation skill based on OSA CNS before and after the training, and to explore correlation between age, gender, interest, level of laparoscopic education, level of laparoscopic experience, and level of laparoscopic knowledge to difference of camera navigation skills after the training. It was novel research due to limited study focused on laparoscopy training program for residency curriculum, especially for camera navigation. In practical setting, camera navigation in teaching hospital often perform by resident and play an important role to support safety laparoscopic procedure.

\section{Materials and Methods}

Study design was experimental study (pre-post interventional study) conducted at the training room of Indonesia Clinical Training and Education Centre (ICTEC) Faculty of Medicine Universitas Indonesia-Dr. Cipto Mangunkusumo Hospital (CMH), on November 2018 to January 2019. Participants were resident of Obstetrics and Gynecology at basic level and work in operating theater. Inclusion criteria were member of residents of Obstetrics and Gynecology, and willing to sign acceptance letter. Exclusion criteria were unable to attend whole research procedure. Sample size was 23 samples, use formula:

$$
n_{1}=n_{2}=\left(\frac{\left(Z_{ \pm}+Z_{2}\right) \mathrm{SD}}{\left(X_{1}-X_{2}\right)}\right)^{2}
$$

$Z_{\alpha}=95 \%=1.96 ; Z_{\beta}=80 \%=1.24 ; \mathrm{SD}=0.5$ (Nilsson) $; X_{1}-X_{2}=$ 0.3. Samples collection used consecutive technique method.

All samples filling in questionnaire about personal data (age, gender, level of residency), level of laparoscopic education, level of laparoscopic experience, and level of laparoscopic knowledge. Level of laparoscopic education and laparoscopic experience were based on fundamentals laparoscopic surgery criteria. Educational level categorized as none, level I, level II, level III, level IV, and

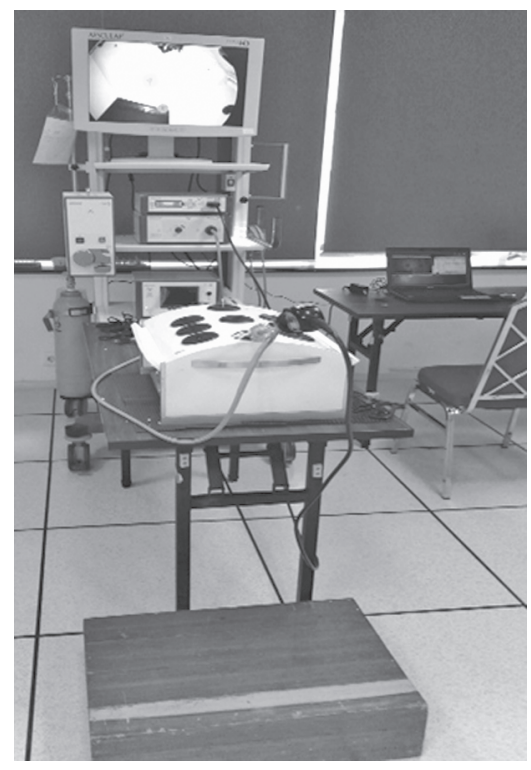

Fig. 1: Pelvic box and laparoscopic camera level V. Experience level classified as low, average, and superior. Laparoscopic knowledge was based on Websurg Winner Project questionnaire that focused on laparoscopic camera equipment and anatomy landmark. The outcome is $\geq 90$ (good) and $<90$ (poor). Interest to laparoscopy measure by Intrinsic Motivation Inventory (IMI) Scale, divided to interested in (score $>6$ ) and not interested in (score $\leq 6)$.

Initial camera navigation evaluation performed used adult pelvic box; laparoscopy camera manufactured by B-Braun (Fig. 1). All these navigations were recorded. Laparoscopy camera navigation training done for about 2 hours. Samples train about laparoscopy camera equipment, how to do appropriate camera navigation, and practice used pelvic box. Post-training evaluation was used the same task of pre-training evaluation (Fig. 2). Evaluation done in 1 week, 2 weeks, and 3 weeks after training. Assessment tool used OSA CNS, consist of five field of evaluation: view completion, horizontal alignment, scope orientation, instrument collision, and autonomy (Fig. 3). Each item with range score 1-5. This evaluation performed by two Oncology Gynecology Consultants who are as advanced laparoscopy trainer. Data are tabulated and analysis used paired- $t$ test of SPSS statistics 20. Flowchart of the research is in Flowchart 1.

\section{Results}

Patient characteristic shows in Table 1. Interest to laparoscopy and level of laparoscopic knowledge are not further analysis for correlation to difference skill after training. It caused by homogeny data.

All of OSA CNS scores after training show significance difference compared to before training score. Three weeks duration after training reveal best optimum time to evaluate camera navigation skill after training (Table 2). Table 3 points out the difference score between three times of evaluation. Table 4 presents gender and level experience are two factors correlated to difference skill after training.

\section{Discussion}

Surgical simulation teaching has become an important training component for many residency programs across all surgical disciplines. After SAGES launched the FLS program in 2004, the American College of Surgeons (ACS) joined SAGES in 2005 for a joint educational effort to establish standards for fundamental skills and knowledge necessary to care for patients undergoing laparoscopic surgery. The growing number of minimally invasive procedures and the need to teach and assess these procedures

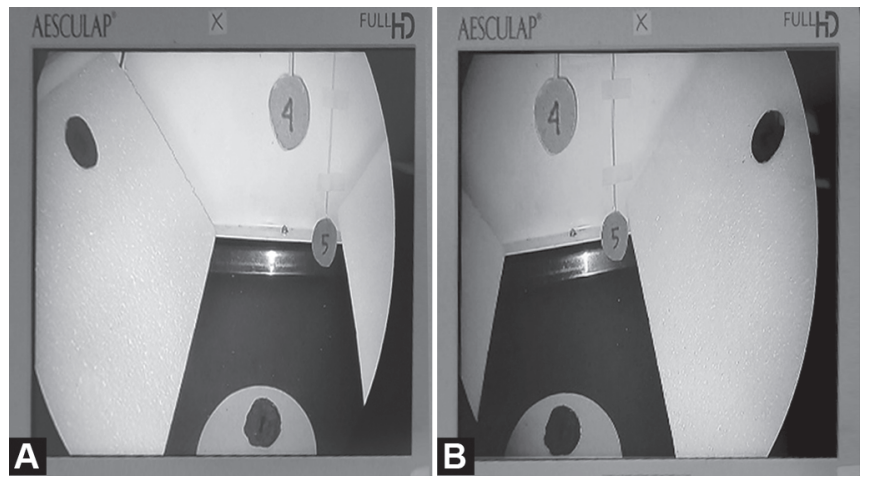

Figs $2 \mathrm{~A}$ and B: Camera navigation task in the pelvic box 
in a simulated setting have been recognized by general surgery residency training programs. ${ }^{1,4,5}$

Live operating theaters should not be the place to start learning surgical skills but rather to consolidate them. Gynecologist should reach competency before operating on a live patient. This may be achieved by training on dry and wet laboratory. Assessment of trainees at the end of a laparoscopic course should cover both knowledge and skills. It can appear overwhelming for a surgical novice to assist during surgery for the first time, and the unfamiliar environment can assumedly compromise focus on the role as an assistant. $^{9}$

In our study, all samples did not have any interest to laparoscopy before the training. And, all of the samples showed level of knowledge below than 90 . Therefore, we did not proceed further analysis for correlation to camera navigation skill after training. On the contrary, we revealed significant difference of OSA CNS score. The IMI is a multidimensional measurement device intended to assess participants subjective experience related to a target activity in laboratory experiments. It has been used in several experiments related to intrinsic motivation and self-regulation. The instrument assesses participants' interest/enjoyment, perceived competence, effort, value/usefulness, felt pressure and tension, and perceived choice while performing a given activity, thus yielding six subscale scores. Meta-analytic study by Scheifele and Krapp about the impact of student interest to learning achievement showed there was other factors that could influence good learning achievement. These factors were motivational factors. ${ }^{10}$ Peyton's four-step approach is becoming more prevalent in medical education. Peyton's four-step approach consists of the following four clearly defined instructional steps: (1) The teacher demonstrates the skill at his normal pace without any comments ("Demonstration"); (2) The teacher repeats the procedure, this time describing all necessary substeps ("Deconstruction"); (3) The student has to explain each substep while the teacher follows the student's instructions ("Comprehension"); (4) The student performs the complete skill on his own ("Performance"). This Peyton's fourstep approach explained contradictive result of low knowledge level but there was increase of camera navigation skill after training used pelvic box in this study. Demonstration and deconstruction appear as important factor in transfer of camera navigation knowledge and skill in this research. ${ }^{11}$

Study by Nilsson stated that the technical aspects of camera navigation skills improve after simulation-based training, but they

\begin{tabular}{|c|c|c|c|}
\hline 1. View completion & 3 & 4 & 5 \\
\hline 1 & 2 & $\begin{array}{c}\text { Can center, size and hold the } \\
\text { visualization filed steady } \\
\text { during most of the procedure }\end{array}$ & $\begin{array}{c}\text { Able to appropriately size, } \\
\text { center and hold the } \\
\text { visualization field steady } \\
\text { at all time }\end{array}$ \\
\hline $\begin{array}{c}\text { Frequently presents a } \\
\text { peripheral part of the } \\
\text { visualization field, with } \\
\text { suboptimal size and/or have } \\
\text { an unsteady hand }\end{array}$ & \begin{tabular}{c} 
and \\
\hline
\end{tabular} \\
\hline
\end{tabular}

2. Horizontal alignment

\begin{tabular}{|c|c|c|c|c|}
\hline 1 & 2 & 3 & 4 & 5 \\
\hline \multicolumn{2}{|c|}{$\begin{array}{c}\text { Repeatedly looses the } \\
\text { horizontal alignment, and are } \\
\text { not able to adjust the axis } \\
\text { when necessary }\end{array}$} & $\begin{array}{l}\text { Keeps the alignment most of } \\
\text { the time, can to some extent } \\
\text { correct the axis when the } \\
\text { operating field moves }\end{array}$ & \multicolumn{2}{|r|}{$\begin{array}{c}\text { Keeps horizontal alignment } \\
\text { and adjust the horizontal axis } \\
\text { when the operating field } \\
\text { moves }\end{array}$} \\
\hline
\end{tabular}

\section{Scope orientation}

\begin{tabular}{|c|c|c|c|c|}
\hline 1 & 2 & 3 & 4 \\
\hline $\begin{array}{l}\text { Troubles with finding and } \\
\text { keeping the correct angle }\end{array}$ & $\begin{array}{c}\text { Keeps an appropriate angle at } \\
\text { most of the time }\end{array}$ & $\begin{array}{c}\text { Angles the scope appropriately } \\
\text { at all time }\end{array}$ & \begin{tabular}{c} 
at \\
\hline
\end{tabular}
\end{tabular}

4. Instrument collision

\begin{tabular}{|c|c|c|c|}
\hline \multicolumn{2}{|c|}{2} & 3 & 4 \\
\hline $\begin{array}{c}\text { Frequent instrument collision } \\
\text { due to inability to retract and } \\
\text { interchange the laparoscope to } \\
\text { avoid instrument collision }\end{array}$ & & $\begin{array}{c}\text { Avoid instrument collision } \\
\text { most of the time }\end{array}$ & $\begin{array}{c}\text { Avoids instrument collision by } \\
\text { retracting and interchange the } \\
\text { laparoscope at all times }\end{array}$ \\
\hline
\end{tabular}

\section{Autonomy}

\begin{tabular}{|c|c|c|c|c|}
\hline 1 & & 3 & 4 & 5 \\
\hline \multicolumn{2}{|c|}{$\begin{array}{c}\text { Surgeon repeatedly needs to } \\
\text { guide and supervise to obtain } \\
\text { a optimal operating field }\end{array}$} & $\begin{array}{l}\text { Can navigate independently } \\
\text { most of the time, but need } \\
\text { some guidance }\end{array}$ & \multicolumn{2}{|r|}{$\begin{array}{c}\text { Is technical independent, and } \\
\text { do not need guidance from the } \\
\text { surgeon }\end{array}$} \\
\hline
\end{tabular}

Fig. 3: OSA CNS evaluation 
Flowchart 1: Flow diagram of the research

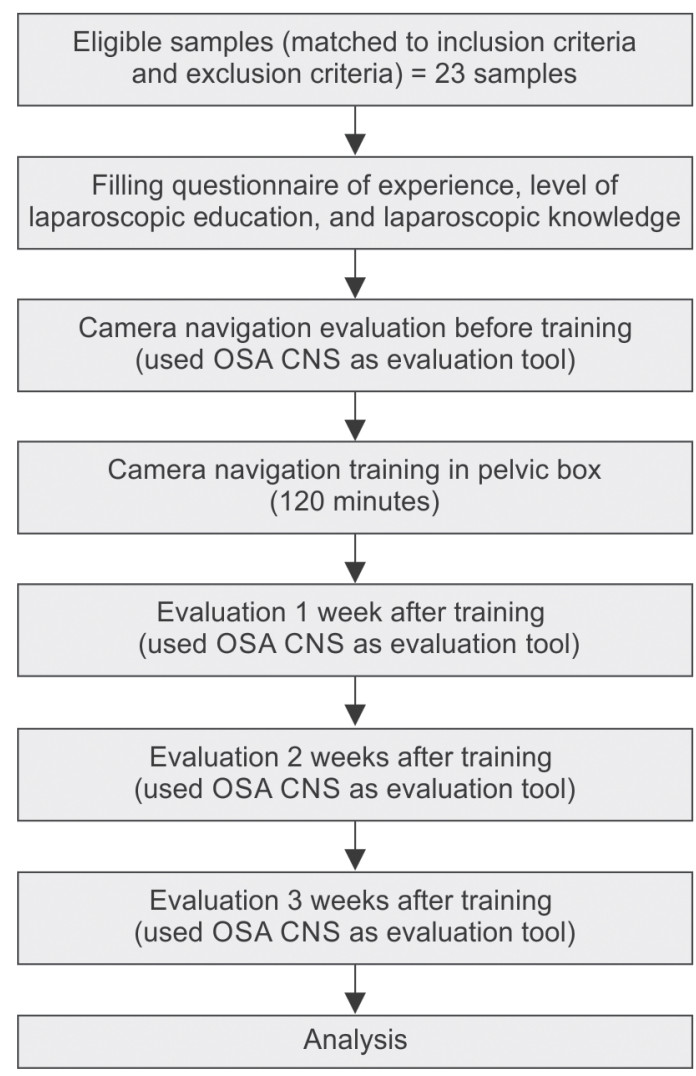

Table 1: Samples characteristic

\begin{tabular}{ll}
\hline Characteristics & Description \\
\hline Age & $29 \pm 3.02$ \\
$\quad<31$ years & $16(69.6 \%)$ \\
$\geq 31$ years & $7(30.4 \%)$ \\
Gender & \\
$\quad$ Male & $15(65.2 \%)$ \\
Female & $8(34.8 \%)$ \\
Interest & \\
$\quad$ Not interest & $23(100 \%)$ \\
Level of laparoscopic education & \\
$\quad$ None & $16(69.6 \%)$ \\
Level I & $7(30.4 \%)$ \\
Level of laparoscopic knowledge & \\
Score $<90$ & $23(100 \%)$ \\
Level of laparoscopic experience & \\
Low & $18(78.3 \%)$ \\
Average & $5(21.7 \%)$ \\
\hline
\end{tabular}

Table 2: OSA CNS score pre- and post-training

\begin{tabular}{llll}
\hline OSA CNS score & Average $\pm S D$ & $p$ value & Difference \\
\hline Pre & $15.00 \pm 2.03$ & Reference & Reference \\
Post I & $17.60 \pm 2.69$ & $<0.001$ & $2.5(-5$ until 8.5$)$ \\
Post II & $16.36 \pm 1.84$ & 0.011 & $2(-3$ until 5.5) \\
Post III & $17.80 \pm 2.26$ & $<0.001$ & $3(-4$ until 6.5) \\
\hline
\end{tabular}

Table 3: OSA CNS score after training

\begin{tabular}{llrl}
\hline & & $n$ & $\%$ \\
\hline \multirow{2}{*}{ 1-week post-training } & Increase & 18 & 78.3 \\
& Decrease-stable & 5 & 21.7 \\
\multirow{2}{*}{ 3-week post-training } & 17 & 73.9 \\
& Increase & 6 & 26.1 \\
& Decrease-stable & 19 & 82.6 \\
& Increase & 4 & 17.4 \\
\hline
\end{tabular}

could not find a significant difference when examining transfer to the OR. ${ }^{6}$ Systematic review by Zendejas et al. showed that virtual simulator training and box training result same outcome of effectiveness laparoscopic skill transfer. Box trainer provides better satisfaction and more time concise. ${ }^{12}$ Loukas et al. also revealed same result in their study. Virtual simulator and pelvic box are equal in laparoscopic skill transfer, i.e., cutting, object transfer, and suturing. ${ }^{13}$

Others interest result in this study, we obtained about 21.7, 26.1, and $17.4 \%$ samples achieve decrease-stable OSA CNS score 1,2 , and 3 weeks after training, respectively. As aim of training, this decrease-stable score is an unexpected outcome. Study by Stucky et al. to evaluate surgeon's work-related symptoms revealed laparoscopy surgeons are significantly more likely to experience musculoskeletal symptoms than surgeons performing surgery. Back pain, neck pain, and arm/shoulder pain are the most anatomy site of musculoskeletal. ${ }^{14}$ In other study by Huang and McGlothlin, concentration is an integral component of ergonomic condition in laparoscopy. Good concentration is parallel to optimal physical condition in laparoscopy. ${ }^{14}$ In our study, fatigue factor probably factor lead to decrease-stable OSA CNS score.

We revealed female gender and low laparoscopic experience are correlated to low OSA CNS score after training. Donnon et al. in their study showed men are having good visuospatial skill than women in case of camera navigation and suturing. Laparoscopy needs good capability to interpret intra-abdominal threedimensional to two-dimensional image on the monitor. ${ }^{15}$ White and Welch in their study about correlation gender to laparoscopic skill mentioned the difference between men and women was occurring before training. Female recommended one-on-one instruction as the most important strategy of completing training outcome. $^{16}$

Laparoscopic experiences are important factor to gain laparoscopic skill after training. This achievement related to exposure to laparoscopy before the training started. Louridas et al. forwarded that experience was factor correlated to accomplish successful laparoscopy training outcome. ${ }^{17}$ As Dawe et al. stated laparoscopic skill of camera navigation and colonoscopy are related to previous experience. ${ }^{18}$

Limitation of this study where we did not compare between training used pelvic box and virtual simulation. We thought it was necessary to know effectively both of training modality in case of preparation all laparoscopic training tools for residency program. Other limitation in our study was did not consider fatigue as confounding factor.

Even with all the limitations, we feel a simulation program focused on teaching fundamental principles and techniques of camera navigation in laparoscopic is a critical component for teaching safe endoscopic practices in our Ob/Gyn residency 
Table 4: Correlation between age, gender, level of laparoscopic education, and level of experience to camera navigation skill difference pre- and post-training

\begin{tabular}{llllll}
\hline & & \multicolumn{3}{c}{ Skill difference } \\
\cline { 3 - 5 } & & Median & Minimum & Maximum & 0.893 \\
\hline Age & $<31$ years & 3.00 & -1.00 & 6.50 & \\
\multirow{2}{*}{ Gender } & $\geq 31$ years & 3.50 & -4.00 & 6.50 & 0.041 \\
& Male & 3.00 & -1.00 & 5.50 & 0.051 \\
Level of laparoscopic & Female & 2.50 & -4.00 & 6.50 & 0.50 \\
education & None & 2.75 & -4.00 & 5.50 & 0.030 \\
Level of laparoscopic & Level I & 3.50 & 2.50 & 6.50 & \\
experience & Low & 3.00 & -4.00 & 5.50 & \\
\hline
\end{tabular}

training program. The growing demand for minimally invasive surgery from our patients, the constant evolution of endoscopic technology and techniques, the limitations of resident work week, and the diverse range of women's healthcare practices (both Obstetrics and Gynecology) that must be mastered in a 4 year training period are some of the challenges of training Ob/Gyn residents today. ${ }^{19}$

\section{Conclusion}

There was significantly different laparoscopy camera navigation skill after training used pelvic box and suggest 3 week duration as optimum time to evaluate training outcome. Female gender and low experience are factors that must notice in training setting to achieve optimum laparoscopy camera navigation training outcome.

\section{Clinical Significance}

Camera navigation training used pelvic box is a critical component for teaching safe endoscopic practices in our Ob/Gyn residency training program.

\section{References}

1. Martin J, Regehr G, Reznick R. Objective Structured Assessment of technical skills (OSATS) for surgical residents. Br J Surg 1997;84(2): 273-278.

2. Elbiss HM, George S, Sidky I, et al. Gynaecological laparoscopy courses in the United arab emirates. Afr Health Sci 2013;13(2):393-401.

3. Buku Rancangan Pengajaran Program Spesialis. Program Studi Dokter Spesialis Obstetri dan Ginekologi Fakultas Kedokteran Universitas Indonesia 2016.

4. Kramp KH, van Det MJ, Hoff C, et al. Validity and reliability of global operative assessment of laparoscopic skills (GOALS) in novice trainees performing a laparoscopic cholecystectomy. J Surg Educ 2015;72(2):351-358.

5. Zheng B, Hur HC, Johnson S, et al. Validity of using fundamentals of laparoscopic surgery (FLS) program to assess laparoscopic competence for gynecologists. Surg Endosc 2010;24(1): 152-160.
6. Nilsson C, Sorensen JL, Konge L, et al. Simulation-based camera navigation training in laparoscopy-a randomized trial. Surg Endosc 2017;31(5):2131-2139.

7. Sroka G, Feldman LS, Vassiliou MC, et al. Fundamentals of laparoscopic surgery simulator training to proficiency improves laparoscopic performance in the operating room-a randomized controlled trial. Am J Surg 2010;199(1):115-120.

8. Vitish-Sharma P, Knowles J, Patel B. Acquisition of fundamental laparoscopic skills: is a box really as good as a virtual reality trainer? Int J Surg 2011;9(8):659-661.

9. Shore EM, Lefebvre GG, Grantcharov TP. Gynecology resident laparoscopy training: present and future. Am J Obstet Gynecol 2015;212(3):298-301, 298 e1.

10. Schiefele U, Krapp A. Interest as a predictor of academic achievement: a meta-analysis of research. Universitat der Bundeswehr 2016. pp. 183-210.

11. Romero P, Gunther P, Kowalewski KF, et al. Halsted's "See one, do one, and teach One" vs Peyton's four-step approach: a randomized trial for training of laparoscopic suturing and knot tying. J Surg Educ 2018;75(2):510-515.

12. Zendejas B, Brydges R, Hamstra SJ, et al. State of the evidence on simulation-based training for laparoscopic surgery: a systematic review. Ann Surg 2013;257(4):586-593.

13. Loukas C, Nikiteas N, Schizas D, et al. A head-to-head comparison between virtual reality and physical reality simulation training for basic skills acquisition. Surg Endosc 2012;26(9):2550-2558.

14. Huang J, McGlothlin JD. Assessment of obstetrician-gynecologists performing laparoscopic surgery: study of hand size and surgical instruments. Journal of Ergonomics 2017;8(1):1-5.

15. Stucky CH, Cromwell KD, Voss RK, et al. Surgeon symptoms, strain, and selections: systematic review and meta-analysis of surgical ergonomics. Ann Med Surg (Lond) 2018;27:1-8.

16. Donnon T, DesCoteaux J, Violato C. Impact of cognitive imaging and sex differences on the development of laparoscopic suturing skills. Can J Surg 2004;48(5):387-393.

17. White MT, Welch K. Does gender predict performance of novices undergoing fundamentals of laparoscopic surgery (FLS) training? Am J Surg 2012;203(3):397-400; discussion.

18. Louridas M, Quinn LE, Grantcharov TP. Predictive value of background experiences and visual spatial ability testing on laparoscopic baseline performance among residents entering postgraduate surgical training. Surg Endosc 2016;30(3):1126-1133.

19. Dawe SR, Pena GN, Windsor JA, et al. Systematic review of skills transfer after surgical simulation-based training. Br J Surg 2014;101(9):1063-1076. 